\title{
Popper's Paradoxical Pursuit of Natural Philosophy
}

Nicholas Maxwell

(To be published in J. Shearmur and G. Stokes, eds., 2016, Cambridge Companion to Popper, Cambridge University Press, Cambridge.)

\begin{abstract}
Popper's pursuit of natural philosophy is paradoxical because his most famous contribution, his demarcation criterion, dissociates science from philosophy, when natural philosophy requires their synthesis. But Popper's demarcation criterion must be rejected. Physics only accepts unified theories, even though endlessly many empirically more successful disunified rivals can always be concocted. This means physics makes a substantial, implicit metaphysical assumption, which needs to be made explicit as an integral part of scientific knowledge. Popper's later views concerning metaphysical research programmes are important but do not go far enough. A solution to the problem of what it means to say a theory is unified is proposed, a problem Popper failed to solve. In The Logic of Scientific Discovery, Popper made important contributions to the interpretation of quantum theory, especially in connection with Heisenberg's uncertainty relations. His later advocacy of the statistical interpretation of quantum theory is less successful. Popper argued against physicalism and the causal closure of the physical universe, but ignored the possibility that the universe might be causally closed but not closed explanatorily, in that phenomena can be explained in at least two kinds of way. Popper's advocacy of natural philosophy has important implications for education.
\end{abstract}

\section{In Praise of Natural Philosophy}

Most philosophers of science assume without question that they pursue a meta-discipline one that takes science as its subject matter, and seeks to acquire knowledge and understanding about science without in any way affecting, or contributing to, science itself. Karl Popper's approach is very different. His first love is natural philosophy or, as he would put it, cosmology. He expresses the point eloquently in "Back to the Presocratics":

There is at least one philosophical problem in which all thinking men are interested: the problem of understanding the world in which we live; and thus ourselves (who are part of that world) and our knowledge of it. All science is cosmology, I believe, and for me the interest of philosophy, no less than of science, lies solely in its bold attempt to add to our knowledge of the world, and to the theory of our knowledge of the world (Popper, 1963, 136; see also Popper, 1959a, 15).

Popper hopes to contribute to cosmology, to our understanding of the world and our knowledge of it; he is not interested in the philosophy of science narrowly conceived as a metadiscipline dissociated from science itself. And yet, as we shall see in more detail below, Popper's pursuit of cosmology is paradoxical: his best known contribution, his proposed solution to the problem of demarcation, helps to maintain the gulf that separates science from metaphysics, thus fragmenting cosmology into falsifiable science on the one hand, and untestable philosophy on the other.

There are several points to note about Popper's conception of cosmology - or natural philosophy as I prefer to call it. The modern sciences of theoretical physics and cosmology are certainly central to natural philosophy. But to say that is insufficient. For, as Popper repeatedly stresses, one should not take disciplines too seriously. What matters are problems rather than disciplines, the latter existing largely for historical reasons and administrative convenience. The problems of natural philosophy cut across all conventional disciplinary boundaries. How is 
change and diversity to be explained and understood? What is the origin and the overall structure of the cosmos, and what is the stuff out of which it is made? How are we to understand our existence in the cosmos, and our knowledge and understanding, such as it is, of the universe? These problems are central to the "disciplines" of theoretical physics, cosmology, biology, history, the social sciences, and philosophy - metaphysics, epistemology, scientific method and thought on the brain-mind problem, the problem of how the physical universe and the world of human experience are inter-related.

Popper is at pains to emphasize that modern natural philosophy has its roots in the thought of the Presocratics, around two and a half thousand years ago. The Presocratics were the first to struggle with central problems of natural philosophy in something like their modern form. Their ideas, most notably the idea that there is an underlying unity or invariance in nature, the idea of symmetry, and the idea that nature is made up of atoms in motion in the void, have had a major impact on the development of modern science. But Popper goes further than this. He suggests that modern theoretical physics and cosmology suffer from a neglect of the seminal exploration of fundamental problems undertaken by Presocractic philosophers such as Anaximander, Heraclitus, Xenophanes and above all Parmenides: see especially (Popper, 1963, ch. 5; and 1998, ch. 7).

Natural philosophy does not just add to the sciences of theoretical physics, cosmology and biology: it gives to these sciences a particular emphasis, aspiration and interpretation. The task is not merely the instrumentalist one of predicting more and more phenomena more and more accurately; it is rather, to explain and understand. This means, in turn, that theoretical physics, pursued as a part of natural philosophy, seeks to enhance our knowledge and understanding of that aspect of the world that lies behind what can be observed, in terms of which observable phenomena can be explained and understood. It commits physics to attempting "to grasp reality as it is thought independent of observation" (Einstein) And this, in turn has implications for specific issues in physics, such as how we should seek to understand quantum theory, irreversibility, relativity theory, the nature of time.

Philosophy and the philosophy of science, pursued as a part of natural philosophy are, for Popper, very different from the way these disciplines are conceived by most academic philosophers in the $20^{\text {th }}$ century. Philosophy is not a specialized discipline concerned to solve (or dissolve) technical puzzles about the meaning of words. Its primary task is not to engage in conceptual analysis. Rather its task is to try to make a contribution to improving our knowledge and understanding of the universe, and ourselves as a part of the universe, including our knowledge. Philosophy has its roots in problems that lie outside philosophy, in the real world, "in mathematics, for example, or in cosmology, or in politics, or in religion, or in social life" (Popper, 1963, 72). And the philosophy of science ought to be pursued, not as a meta-discipline with science as its object of study, but rather as an integral part of science itself, an integral part of natural philosophy, seeking to help improve our knowledge and understanding of the cosmos, our place in the cosmos, and the miracle of our partial and fallible knowledge of the cosmos.

There is a further point. Popper is adamant that philosophy can learn from science. It is not just that many of the central problems of philosophy have their roots in science. In addition, even though philosophical doctrines, unlike scientific theories, are irrefutable, philosophy can still learn from science how to go about tackling its problems so that progress is made in a way somewhat analogous to progress achieved in science. Philosophical doctrines, even though irrefutable, can be critically assessed from the standpoint of their capacity to solve the problems they were put forward to solve. A generalization of the falsificationist, progress-achieving methods of science - namely critical rationalism - can be put into practice in philosophy so that progress can be made in solving philosophical problems too.

Popper's passionate endorsement of cosmology, or natural philosophy, comes with a fierce condemnation of specialization and what Thomas Kuhn called "normal science". The natural 
philosopher should forego the spurious authority of the expert, and should do his best to communicate simply and clearly, without jargon and, as far as possible, without technicalities only comprehensible to specialists. Natural philosophy needs the love and participation of amateurs; it dies when it becomes the exclusive preserve of professionals.

Did Popper really give his primary allegiance to natural philosophy ${ }^{1}$ as I have just characterized it? The following quotations from Popper, in addition to the two given above, show, I think, that he did.

The belief that there is such a thing as physics, or biology, or archaeology, and that these 'studies' or 'disciplines' are distinguishable by the subject matter which they investigate, appears to me to be a residue from the time when one believed that a theory had to proceed from a definition of its own subject matter. But subject matter, or kinds of things, do not, I hold, constitute a basis for distinguishing disciplines. Disciplines are distinguished partly for historical reasons and reasons of administrative convenience (such as the organization of teaching and of appointments), and partly because the theories which we construct to solve our problems have a tendency to grow into unified systems. But all this classification and distinction is a comparatively unimportant and superficial affair. We are not students of some subject matter but students of problems. And problems may cut across the borders any subject matter or discipline (Popper, 1963, 66-7).

Genuine philosophical problems are always rooted in urgent problems outside philosophy, and they die if these roots decay" (Popper, 1963, 72). "For me, both philosophy and science lose all their attraction when they become specialisms and cease to see, and to wonder at, the riddles of our world. Specialization may be a great temptation for the scientist. For the philosopher it is the mortal sin (Popper, 1963, 136). [T] he 'philosophy of science' is threatening to become a fashion, a specialism. Yet philosophers should not be specialists. For myself, I am interested in science and in philosophy only because I want to learn something about the riddle of the world in which we live, and the riddle of man's knowledge of that world. And I believe that only a revival of interest in these riddles can save the sciences and philosophy from narrow specialization and from an obscurantist faith in the expert's special skill and in his personal knowledge and authority; a faith that so well fits our 'post-rationalist' and 'post-critical' age, proudly dedicated to the destruction of the tradition of rational philosophy, and of rational thought itself (Popper, 1959a, 23).

The First World War destroyed not only the commonwealth of learning; it very nearly destroyed science and the tradition of rationalism. For it made science technical, instrumental. It led to increased specialization and it estranged from science what ought to be its true users - the amateur, the lover of wisdom, the ordinary, responsible citizen who has a wish to know . . . our Atlantic democracies cannot live without science. Their most fundamental value - apart from helping to reduce suffering - is truth. They cannot live if we let the tradition of rationalism decay. But what we can learn from science is that truth is hard to come by: that it is the result of untold defeats, of hearbreaking endeavour, of sleepless nights. This is one of the great messages of science, and I do not think that we can do without it. But it is just this message which modern specialization and organized research threatens to undermine (Popper, 1983, 260).

If the many, the specialists, gain the day, it will be the end of science as we know it - of great science. It will be a spiritual catastrophe comparable in its consequences to nuclear armament (Popper, 1994, 72). ${ }^{2}$ 


\section{Demarcation, Metaphysics and Unity}

Popper's rediscovery, advocacy, and celebration of natural philosophy is, in my view, of great importance, both intellectually and educationally. But it is, as I have already indicated, paradoxical.

Natural philosophy flourished in the $16^{\text {th }}, 17^{\text {th }}$ and $18^{\text {th }}$ centuries, but then suffered a severe setback when Newton's ideas about scientific method became generally accepted, along with his contributions to physics. Newton famously declared "I frame no hypotheses", and claimed to derive his law of gravitation from the phenomena, employing his rules of reason. Subsequently, natural philosophers - or scientists - sought to tread in Newton's footsteps, by deriving new laws from the phenomena by means of induction. Natural philosophers no longer needed, it seemed, to engage in debates about metaphysics, epistemology and methodology. ${ }^{3}$ Newton had provided a definite method for scientists to follow which undeniably worked. Natural philosophy became science. This splitting of natural philosophy into science on the one hand, and philosophy on the other, was reinforced by work produced by "the philosophers". Descartes and Locke struggled to make sense of the metaphysical view of the world of the new natural philosophy, and came up with Cartesian Dualism and the representational theory of perception. Their successors Berkeley, Hume, Kant and others - struggling with the problems bequeathed to them by Descartes and Locke, produced work increasingly remote from science. Eventually, philosophy itself split into two non-communicating schools, so-called "continental" and "analytic" philosophy, both remote from science, and the very idea that modern philosophy had begun by trying to make sense of the metaphysics of physics was entirely lost sight of. Natural philosophy all but disappeared.

In view of this massive historical progression, Popper's attempted resurrection of natural philosophy is little short of heroic. Nevertheless, paradoxically, Popper's most famous contribution actually serves to maintain the traditional split between science and philosophy, and in this way serves to continue the suppression of natural philosophy. Popper makes clear near the beginning of his The Logic of Scientific Discovery that, in his view, the problem of demarcating science from metaphysics is the fundamental problem in the theory of knowledge (Popper, 1959a, 34), a point often echoed subsequently: see for example (Popper, 1963, 42; 1972 , 29-31; 1974, 976; 1976, 79; and 1983, 159-63). His solution, of course, is that theories that are scientific are empirically falsifiable: metaphysical and philosophical ideas, being unfalsifiable, are not scientific. That scientific theories are falsifiable is the key idea of Popper's philosophy of science. Inductivism is fiercely repudiated, but nevertheless the split between physics and metaphysics, stemming from Newton, is maintained. Metaphysical ideas can be, for Popper, meaningful, and may even play an important role in science in the context of discovery. But discovery is not rational; it is not "susceptible" to "logical analysis" (Popper, 1959a, 31), and is not subject to scientific method. Metaphysics is not, for Popper, a part of scientific knowledge; it has no rational role to play within science (even though metaphysics may be pursued rationally, that is critically, and may itself learn from science). ${ }^{4}$

If Popper's solution to the demarcation problem was basically sound, it would place a serious limitation on the scope and viability of natural philosophy, which is based on the integration of science and metaphysics. But it is not sound. It is quite fundamentally defective. Once this point has been appreciated, it becomes apparent that a new conception of natural philosophy is required, one that fully integrates science, metaphysics, methodology and philosophy of science in a way which is fully Popperian in spirit, even though it clashes with a number of Popper's views, as we shall see. Both the successes and the failings of Popper's rediscovery of natural philosophy can only be fully appreciated if one recognizes just how powerful - how powerfully Popperian - are the arguments in support of the fully integrated conception of natural philosophy I shall now briefly indicate. I here summarise an argument I have developed over many years: 
see (Maxwell, 1974; 1976a, chs. 5 and 6; 1993; 1998; 2002; 2004a; 2004c; 2005; 2007; 2008; 2011b; 2013; and forthcoming).

One of the great themes of Popper's philosophy is that we learn through criticism, through subjecting our attempted solutions to problems to critical scrutiny. Falsification is, for Popper, an especially severe form of criticism. This idea requires that assumptions that are substantial, influential, problematic and implicit be made explicit so that they can be subjected to critical scrutiny. If assumptions such as these lurk within science, implicit and unacknowledged, then these assumptions need to be made explicit within science, so that they can be criticized and, we may hope, improved. Just such assumptions do indeed lurk, unacknowledged, within science. They need to be made explicit so that they can be criticized.

Physicists only accept theories that are unified. That is, in order to be acceptable, a physical theory must be such that its content, what it asserts about the world (rather than its form or axiomatic structure) is the same throughout the phenomena to which it applies. Newtonian theory is unified because the same laws, $\mathrm{F}=$ ma and $\mathrm{F}=\mathrm{Gm}_{1} \mathrm{~m}_{2} / \mathrm{d}^{2}$, apply to all the phenomena to which the theory is applicable. A version of Newtonian theory which asserts that these laws apply up till midnight, but afterwards $\mathrm{F}=\mathrm{Gm}_{1} \mathrm{~m}_{2} / \mathrm{d}^{3}$ applies, is disunified because different laws apply before and after midnight. Such disunified theories are never considered in physics. Physics only considers, and certainly only accepts, theories that are unified in the sense that the same laws apply to all the phenomena within the scope of the theory in question. In order to be explanatory, a physical theory must be unified in this sense. A theory that asserted that quite different laws applied for different phenomena might predict, but it would not explain. (Consider, for example, the extreme case of a theory which just consists of all the diverse empirical laws governing the diverse phenomena to which the theory applies. Such a theory would predict but, quite clearly, would not explain.)

Given any accepted (unified) physical theory, there will always be endlessly many easily formulatable, empirically more successful, but disunified rivals. (All physical theories are ostensibly refuted by some empirical phenomena; disunified rivals can easily be concocted to give the correct predictions for these recalcitrant phenomena. In addition, independently testable and corroborated hypotheses can be tacked on, to create empirically more successful theories.) Thus physics persistently accepts unified theories in the teeth of endlessly many empirically more successful (but disunified) rivals. This means that physics persistently, if implicitly, accepts a metaphysical thesis, to the effect that no disunified theory is true.

If physicists only accepted theories that postulate atoms, and persistently rejected theories that postulate different physical entities, such as fields - even though many field theories can easily be, and have been, formulated which are even more empirically successful than the atomic theories - the implication would surely be quite clear. Physicists would in effect be assuming that the world is made up of atoms, all other possibilities being ruled out. The atomic assumption would be built into the way the scientific community accepts and rejects theories built into the implicit methods of the community, methods which include: reject all theories that postulate entities other than atoms, whatever their empirical success might be. The scientific community would accept the assumption: the universe is such that no non-atomic theory is true.

Just the same holds for a scientific community that rejects - that does not even consider - all disunified rivals to accepted theories, even though these rivals would be even more empirically successful if they were considered. Such a community in effect makes the assumption: the universe is such that no disunified theory is true. ${ }^{5}$

This assumption, however precisely interpreted (see below), is neither falsifiable nor verifiable. For, given any accepted physical theory, T, there will be infinitely many empirically more successful disunified rivals, $\mathrm{T}_{1}, \mathrm{~T}_{2}, \ldots \mathrm{T}_{\infty}$. The assumption in question, then, asserts "not $\mathrm{T}_{1}$ and not $\mathrm{T}_{2}$ and $\ldots$ not $\mathrm{T}_{\infty}$ ". This assumption cannot be falsified, because this would require that just one of $T_{1}, T_{2}, \ldots$ or $T_{\infty}$ is verified, but physical theories cannot be verified. The 
assumption cannot be verified either, because this would require that all of $T_{1}, T_{2}, \ldots T_{\infty}$ are falsified, which is not possible since there are infinitely many theories involved. Being neither falsifiable nor verifiable, the assumption is metaphysical. (For Popper, in order to be metaphysical, it suffices that the assumption is not falsifiable.) But this assumption, despite its metaphysical character, is nevertheless such a secure part of scientific knowledge that endlessly many theories, empirically more successful than accepted theories, are rejected (or rather are not even considered) solely because they conflict with the assumption. Popper's own requirements for intellectual integrity and rationality require that this usually implicit and unacknowledged metaphysical component of scientific knowledge be made explicit so that it can be criticized and, perhaps, improved. But this conflicts with, and refutes, Popper's solution to the problem of demarcation. It leads, as we shall see, for wholly Popperian reasons, to a conception of science that integrates falsifiable theory and unfalsifiable metaphysics. It requires, furthermore, that the philosophy of science be an integral part of science itself. The upshot is natural philosophy, full-blooded to an extent that Popper could not envisage, upholding as he did, to the end, his demarcation criterion. ${ }^{6}$

If it was clear what the assumption "all disunified theories are false" should be taken to be, the outcome of the argument, outlined above, would not be of much importance. What makes it of very great importance is that it is both unclear as to what the assumption should be, and of profound significance for theoretical physics that a good choice of assumption is made. But before I can establish these two points I must first solve the problem of what it is for a physical theory to be unified or simple.

\section{The Problem of the Unity or Simplicity of Physical Theory}

It is widely recognized that, when it comes to judging whether a physical theory should be accepted, its unity or simplicity is an important consideration in addition to its empirical success or failure. It is also widely recognized that the unity or simplicity of a theory poses a profound problem. There are two problems. First, what is unity or simplicity? Second, what rationale can there be for preferring unified or simple theories to disunified, complex ones?

Explicating what unity or simplicity is poses a problem because a unified, simple theory can always be reformulated so as to come out as horrendously disunified and complex, and vice versa, a horribly disunified, complex theory can always be reformulated so as to come out as dazzlingly unified and simple.

Richard Feynman (Feynman et al., 1965, vol. ii, 25, 10-11) gives a beautiful example of the latter process. Consider an appallingly disunified, complex theory, made up of $10^{10}$ quite different, distinct laws, stuck arbitrarily together. Such a theory can easily be reformulated so that it reduces to the dazzlingly unified, simple form: $A=0$. Suppose the $10^{10}$ distinct laws of the universe are: (1) $\mathrm{F}=\mathrm{ma}$; (2) $\mathrm{F}=\mathrm{Gm}_{1} \mathrm{~m}_{2} / \mathrm{d}^{2}$; and so on, for all $10^{10}$ laws. Let $\mathrm{A}_{1}=(\mathrm{F}-\mathrm{ma})^{2}$, $\mathrm{A}_{2}=\left(\mathrm{F}-\mathrm{Gm}_{1} \mathrm{~m}_{2} / \mathrm{d}^{2}\right)^{2}$, and so on. Let $\mathrm{A}=\mathrm{A}_{1}+\mathrm{A}_{2}+\ldots+\mathrm{A}_{1010}$. The theory can now be formulated in the unified, simple form $A=0$. (This is true if and only if each $A_{r}=0$, for $\left.\mathrm{r}=1,2, \ldots 10^{10}\right)$.

The reverse process can be performed with equal ease. Given any genuinely unified, simple theory, such as Newtonian theory say, special terminology can always be defined such that, when the theory is formulated in this terminology, it comes out as horribly disunified and complex (as we shall see below).

The problem is to say what unity or simplicity is, and why it is important for science, given that it is so wholly dependent on choice of terminology.

This has long been recognized as a major problem in the philosophy of science. Einstein $(1949,23)$ recognized the problem and confessed he did not know how to solve it. There is now a vast literature expounding failed attempts at solving the problem: see Salmon (1989) and Maxwell (1998, 56-68). 
In The Logic of Scientific Discovery, Popper sought to solve the problem by identifying simplicity with falsifiability (Popper, 1959a, chapter VII). But this proposed solution fails. Given a theory, $\mathrm{T}$, one can easily increase the degree of falsifiability of $\mathrm{T}$ by adding on additional, independently testable theories, $T_{1}, T_{2}, \ldots T_{n}$ to form $T+T_{1}+T_{2} \ldots+T_{n}$. This latter theory is clearly of greater falsifiability than T. But, in general, it will be, not simpler or more unified than $\mathrm{T}$, but vastly more complex and disunified. Thus simplicity cannot possibly be identified with falsifiability. ${ }^{7}$ (This argument refutes, not just Popper's theory of simplicity, but his basic doctrine of falsificationism. If $\mathrm{T}_{1}, \mathrm{~T}_{2}, \ldots \mathrm{T}_{\mathrm{n}}$ are not just independently testable, but have also been empirically corroborated then, according to Popper's methodology,

$\mathrm{T}+\mathrm{T}_{1}+\mathrm{T}_{2} \ldots+\mathrm{T}_{\mathrm{n}}$ should replace $\mathrm{T}$, because the former theory is more falsifiable and its excess empirical content has been corroborated. But in scientific practice, quite properly, $\mathrm{T}+\mathrm{T}_{1}+\mathrm{T}_{2} \ldots+\mathrm{T}_{\mathrm{n}}$ would never be considered for a moment, let alone be accepted. Falsificationism is straightforwardly refuted by proper scientific practice.)

Subsequently, in Conjectures and Refutations, Popper made another suggestion concerning simplicity. He asserts:

[A] new theory should proceed from some simple, new, and powerful, unifying idea about some connection or relation (such as gravitational attraction) between hitherto unconnected things (such as planets and apples) or facts (such as inertial and gravitation mass) or new 'theoretical entities' (such as field and particles). This requirement of simplicity is a bit vague, and it seems difficult to formulate it very clearly. It seems to be intimately connected with the idea that our theories should describe the structural properties of the world - an idea which it is hard to think out fully without getting involved in an infinite regress (Popper, 1963, 241).

This gives an excellent intuitive feel for the idea of theoretical unity but hardly solves the problem, as Popper himself in effect admits in the above passage.

I now indicate how the problem is to be solved. All I do here is sketch the solution that I have expounded in much greater detail elsewhere (see Maxwell, 1998, especially chapters 3 and 4; 2004a, appendix, section 2; and 2004c).

The decisive point to recognize (already hinted at above) is that the unity and simplicity of a physical theory have to do, not with the form of the theory, its axiomatic structure or patterns of derivations, but with its content, with what it asserts about the world. In order to solve the problem we need to look, not at the theory itself (which is what previously has been done), but at the world - or rather at what the theory asserts about the world. And the crucial requirement a dynamical physical theory must satisfy to be unified is that it is such that it asserts that, throughout the range of phenomena, actual and possible, to which the theory applies, the same laws govern the way these phenomena evolve in space and time. ${ }^{8}$ A theory that asserts that one set of laws apply to one range of phenomena, and a different set of laws apply to a different set of phenomena is, to that extent, disunified. And the greater the number of different sets of laws the theory postulates for different ranges of phenomena, so the more disunified the theory is. This provides us with a way of specifying the degree of disunity of a theory. A theory that asserts that different sets of laws apply in $\mathrm{N}$ different ranges of phenomena (to which the theory applies) is disunified to degree $\mathrm{N}$. For unity, we require that $\mathrm{N}=1$.

It is at once clear that the fact that theories can be reformulated, so that a simple, unified formulation becomes complex and disunified, and vice versa, is no longer a problem. As long as these reformulations leave the content of the theories in question unaffected (as the objection presupposes), they do not affect the degree of unity of the theory, as this has just been explicated.

There is a further refinement. Given a theory that is disunified to degree $N>1$, the question can arise as to how different, in what way different, are laws in one range of phenomena from 
laws in another range of phenomena. Some ways in which sets of laws can differ, one from the other, can be much more dramatic, much more serious, than other ways. This gives rise to different kinds of disunity, some being much more serious than others.

Here are five different ways in which dynamical laws can differ for different ranges of phenomena, and thus five different kinds of disunity.

(1) T differs in $\mathrm{N}$ different spacetime regions. Example: The disunified version of Newtonian theory indicated above, with

$\mathrm{F}=\mathrm{Gm}_{1} \mathrm{~m}_{2} / \mathrm{d}^{2}$ up to midnight tonight, and $\mathrm{F}=\mathrm{Gm}_{1} \mathrm{~m}_{2} / \mathrm{d}^{3}$ after midnight. Here, $\mathrm{T}$ is disunified to degree $\mathrm{N}=2$ in a type (1) way.

(2) $\mathrm{T}$ differs in $\mathrm{N}$ distinct ranges of physical variables other than position or time. Example: $\mathrm{F}=\mathrm{Gm}_{1} \mathrm{~m}_{2} / \mathrm{d}^{2}$ for all bodies except for those made of gold of mass greater than 1,000 tons in outer space within a region of 1 mile of each other, in which case $F=\mathrm{Gm}_{1} \mathrm{~m}_{2} / \mathrm{d}^{4}$. Here, $T$ is disunified to degree $\mathrm{N}=2$ in a type (2) way.

(3) T postulates N-1 distinct, spatially localized objects, each with its own unique dynamic properties. Example: $\mathrm{T}$ asserts that everything occurs as Newtonian theory asserts, except there is one object in the universe, of mass 8 tons, such that, for any matter up to 8 miles from the centre of mass of this object, gravitation is a repulsive rather than attractive force. The object only interacts by means of gravitation. Here, $\mathrm{T}$ is disunified to degree $\mathrm{N}=2$, in a type (3) way.

(4) $\mathrm{T}$ postulates $\mathrm{N}$ distinct forces. Example: $\mathrm{T}$ postulates particles that interact by means of Newtonian gravitation; some of these also interact by means of an electrostatic force $\mathrm{F}=\mathrm{Kq}_{1} \mathrm{q}_{2} / \mathrm{d}^{2}$, this force being attractive if $\mathrm{q}_{1}$ and $\mathrm{q}_{2}$ are oppositely charged, otherwise being repulsive, the force being much stronger than gravitation. Here, $\mathrm{T}$ is disunified to degree $\mathrm{N}=2$ in a type (4) way.

(5) $\mathrm{T}$ postulates one force but $\mathrm{N}$ distinct kinds of particle. Example: $\mathrm{T}$ postulates particles that interact by means of Newtonian gravitation, there being three kinds of particles, of mass $\mathrm{m}, 2 \mathrm{~m}$ and $3 \mathrm{~m}$. Here, $\mathrm{T}$ is disunified to degree $\mathrm{N}=3$ in a type (5) way. ${ }^{9}$

(1) to (5) are to be understood as accumulative, so that each presupposes $\mathrm{N}=1$ as far as its predecessors are concerned.

These five facets of disunity all exemplify, it should be noted, the same basic idea: disunity arises when different dynamical laws govern the evolution of physical states in different ranges of possible phenomena to which the theory $\mathrm{T}$ applies. Thus, if $\mathrm{T}$ postulates more than one force, or kind of particle, then in different ranges of possible phenomena, different force laws will operate. In one range of possible phenomena, one kind of force operates, in another range, other forces operate. Or in one range of phenomena, there is only one kind of particle, while in another range there is only another kind of particle. The five distinct facets of unity, (1) to (5) arise, as I have said, because of the five different ways in which content can vary from one range of possible phenomena to another, some differences being more different than others.

Let me emphasize once again that the above five facets of unity all concern the content of a theory, and not its form, which may vary drastically from one formulation to another. One might, for example, split space up into $\mathrm{N}$ regions, and introduce special terminology for each region so that Newton's laws look very different as one goes from one spatial region to another.

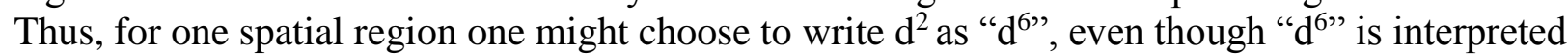
to assert $\mathrm{d}^{2}$. As one goes from region to region, the form of the theory, what is written down on paper, varies dramatically. It might seem that this is a theory disunified to degree $\mathrm{N}$ in a type (1) way - the most serious kind of disunity of all. But as long as what is asserted, the content, is the same in all spatial regions, the theory is actually unified in a type (1) way, with $\mathrm{N}=1 .{ }^{10}$

It deserves to be noted in passing that this solution to the problem of what it means to say of a theory that it is unified or simple also solves the problem of what it means to say of a theory that it is explanatory. In order to be explanatory, a theory must (a) be unified and simple and (b) of high empirical content. 
It also deserves to be noted that Popper quite explicitly demands that an acceptable physical theory must satisfy the first of the above five kinds of unity (with $\mathrm{N}=1$ ): see Popper (1959a, sections 13-15 and 79). What Popper did not appreciate is that an extension of this requirement of invariance with respect to space and time to include (2) to (5) as well, goes a long way to solving the problem of simplicity or unity of theory. He comes closest to this, perhaps, in Popper (1998, ch. 7), but still does not, there, make the decisive point (see note 8).

\section{The Hierarchical View and Scientifically Essential and Fruitful Metaphysics}

In section 2 above we saw that persistent preference in physics for unified theories over empirically more successful, disunified rivals means that physics makes a persistent metaphysical assumption about the universe, namely: it is such that all disunified theories are false. But now we see that this assumption is open to a range of interpretations, depending on whether we interpret "disunified" to mean "disunified in a type (1), type (2) ... or type (5) way". We have before us, then, five metaphysical theses which I shall formulate as "The universe is such that there is a true physical theory of everything which is unified $(\mathrm{N}=1)$ in a type $(\mathrm{r})$ way, with $r=1,2, . .5$ ". These five theses become increasingly substantial, increasingly contentful, as $r$ goes from 1 to 5. Let us call these five theses "physicalism(r)". If $r_{2}>r_{1}$ then physicalism $\left(r_{2}\right)$ implies - but is not implied by - physicalism( $\left.\mathrm{r}_{1}\right)$. And even more substantial metaphysical theses are available, asserting that the universe is unified, or physically comprehensible (in the sense that one kind of physical explanation exists for all physical phenomena). An example is the thesis that the universe is such that the true physical theory of everything is unified in the very strong sense that it unifies matter and space-time into one entity. I shall call this thesis physicalism(6).

Which of these available metaphysical theses concerning the dynamical unity of the universe should be accepted by physics as a part of current theoretical scientific knowledge? Some such thesis $i$ accepted, and must be accepted, as we saw in section 2. It is enormously important, for the progress of theoretical physics, that a good choice of assumption is made. For this assumption determines what theories physicists accept and reject on non-empirical grounds; and it also determines in what directions physicists look in seeking to develop new, better fundamental theories. In other words, the assumption is important in the contexts of both discovery and acceptance. If we are fortunate in making an assumption that is true, this will enormously help progress in theoretical physics. But if we make an assumption that is badly false, as seems all too likely, this will very seriously impede progress. Whatever assumption we make, it will be substantial, influential and problematic, all too likely to be false. It thus cries out to be made explicit and thus subject to critical scrutiny within science.

How do we choose? Two conflicting lines of argument lead to two very different choices. On the one hand we may argue that that assumption should be accepted which has the least content which is just sufficient to exclude the empirically successful disunified theories that current methods of physics do exclude (although it is not easy to see what the assumption, chosen on these grounds, should be). On the other hand, we may argue that that assumption should be accepted which can be shown to be the most conducive to progress in theoretical physics so far. This latter line of argument is thoroughly Popperian in character. The whole point of criticism, for Popper, is to further the growth of knowledge. It makes perfect sense to accept, conjecturally, that assumption which seems to be the most fruitful from the standpoint of scientific fruitfulness, its capacity to help promote the growth of scientific knowledge, and then subject it to sustained criticism from that standpoint.

How can we do justice to these two conflicting desiderata?

The solution is to satisfy both by adopting not one, but a hierarchy of assumptions: see diagram. ${ }^{11}$ At levels 1 to 6 the universe is asserted to be such that the yet-to-be-discovered true physical theory of everything is unified $(\mathrm{N}=1)$ in the increasingly demanding senses of 


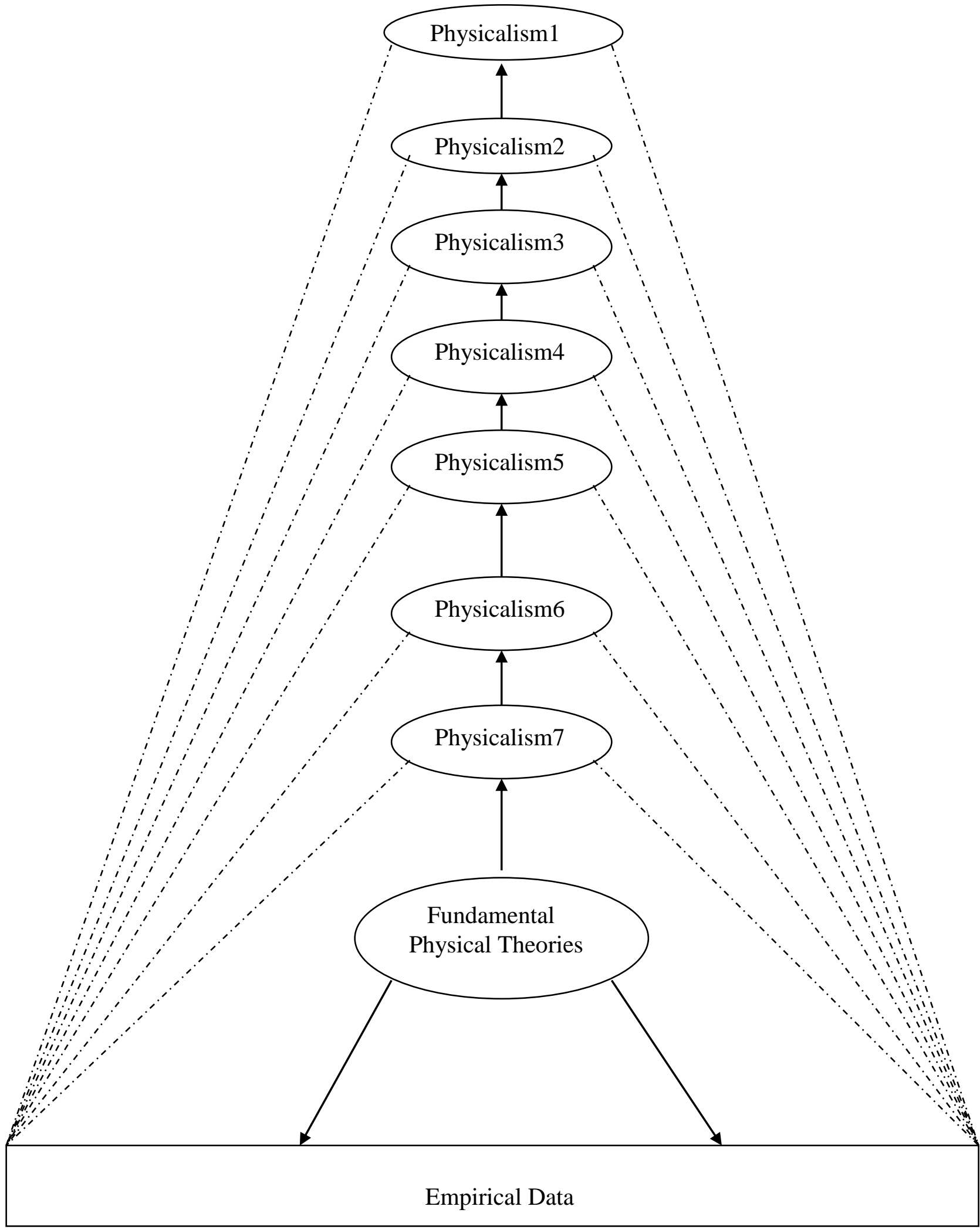

Diagram 
"unified" spelled out in $r=1$ to 6 above. As we descend the hierarchy, the metaphysical theses, versions of physicalism, become increasingly contentful, potentially increasingly fruitful in helping to promote scientific progress, but also increasingly likely to be false, and in need of revision. Associated with each version of physicalism there is a corresponding non-empirical methodological principle, represented by dotted lines in the diagram, which constrains acceptance of theses and falsifiable theories lower down in the hierarchy.

At level 7 there is an even more contentful, precise version of physicalism, very likely to be false, which specifies the kind of physical entities - or entity - everything is made up of. Examples of theses that have been presupposed at this level 7, taken from the history of physics, include the following. The universe is made up of tiny hard corpuscles which interact only by contact. It is composed of point-atoms which have mass and are surrounded by a rigid, spherically-symmetrical field of force which is centrally directed. It is composed of a unified, self-interacting field. It is made up of a quantum field. There is only empty spacetime, matter being no more than a kind of topologically complex quantum foam of empty spacetime. Everything is composed of some kind of quantum string field in ten or eleven dimensions. ${ }^{12}$

At level 8 there are the currently accepted fundamental theories of physics, at present the quantum field theory of fundamental particles and the forces between them (the so-called standard model) and Einstein's general theory of relativity. At level 9 there are accepted empirical phenomena, low-level empirical laws.

The thesis at level 7 is almost bound to be false (even if physicalism(6) or physicalism(5) is true), just because it is so specific and precise. (The less you say, other things being equal, the more likely it is that what you say is true. "Ultimate reality is not a chicken" is almost bound to be true of ultimate reality just because there are so many ways of not being a chicken.) The grounds for accepting physicalism(6) are that this thesis is implicit in the non-empirical methods of theoretical physics, and is the thesis that is the most fruitful, the most conducive to progress in theoretical physics, at that level of generality. Other things being equal, the more nearly a new fundamental physical theory satisfies all six of the above requirements for unity, with $\mathrm{N}=1$, the more acceptable it would be deemed to be. Furthermore, all new fundamental physical theories, from Newton to today, have brought greater unity to theoretical physics, in one or other of the above five or six senses.

This hierarchical view accords perfectly with the spirit, if not the letter, of Popper's critical philosophy. The idea is to make explicit, and so criticizable and, we may hope, improvable, assumptions implicit in the (non-empirical) methods of physics. ${ }^{13}$ The hierarchical view does justice to the two conflicting desiderata indicated above, as no view which specifies just one (possibly composite) metaphysical assumption can do.

So, to sum up, the basic idea behind this hierarchical view can be put like this. For science to proceed, and for the enterprise of acquiring knowledge to proceed more generally, an untestable, metaphysical assumption must be made about the nature of the universe. In order to meet with success we need to make an assumption that is fruitful and true, but the chances are that the assumption we make will be false. Granted this, in order to give ourselves the best chance of making progress in acquiring knowledge, we need to make, not just one, but a hierarchy of assumptions, these assumptions becoming increasingly insubstantial, and so increasingly likely to be true, as we ascend the hierarchy. We make those assumptions which seem to be implicit in our apparently most successful ventures at improving knowledge, and which seem to be inherently fruitful for improving knowledge, if true. The hierarchy, initially, simply makes explicit what is implicit in what seem to be our most successful efforts at acquiring knowledge. We then revise metaphysical assumptions, and associated methodological rules, in the light of which seem to lead to the most empirically successful research programmes, but in such a way that we keep such revisions as low down in the hierarchy of assumptions as possible. Only when efforts at acquiring knowledge seem to be meeting with little success do we actively consider 
more radical revisions higher up in the hierarchy. We conjecture that the top level 1 assumption of the diagram is true, ${ }^{14}$ and the bottom level 7 assumption is false. As we descend from 1 to 7 , at some point we move from truth to falsity, and thus to an assumption which needs to be revised. Our hope is that as we proceed, and learn more about the nature of the universe, we progressively bring truth lower and lower down in the hierarchy. Criticism is concentrated where it is most likely to be fruitful, low down in the hierarchy. Furthermore, the framework of relatively unproblematic assumptions and associated methods, high up in the hierarchy, helpfully restrict ideas about how to improve assumptions low down in the hierarchy to just those most likely to be fruitful for progress. As our knowledge improves, assumptions and associated methods improve as well. There is positive feedback between improving knowledge and improving assumptions and methods - that is, knowledge-about-how-to-improve-knowledge. This positive feedback between improving knowledge, and improving knowledge-about-how-toimprove-knowledge is the sine qua non of scientific methodology and rationality. As science improves its knowledge and understanding of nature, it adapts its own nature to what it has discovered. The astonishing progressive success of science in improving our knowledge and understanding of nature owes much to the exploitation of this positive feedback, metamethodological feature of the hierarchical view in scientific practice. (Even though the scientific community has officially upheld the orthodox view that there are no metaphysical assumptions implicit in the methods of science, fortunately its allegiance to this doctrine has been sufficiently hypocritical to make it possible to implement something close to the hierarchical view in scientific practice.)

\section{Metaphysical Research Programmes}

This hierarchical conception of natural philosophy captures much of what Popper seems to have had in mind in writing of "cosmology", "great science", and "metaphysical research programmes". It is clear, however, that Popper did not adopt the view, and it is this, to my mind at least, which makes Popper's pursuit of natural philosophy paradoxical. Popper did not abandon his demarcation requirement, which one must do if the hierarchical view is to be accepted. Popper failed to solve the problem of simplicity, encapsulated in the above five facets of unity, and an essential ingredient of the hierarchical view. Popper argued for the causal openness of the physical universe, and for "downward causation", especially in connection with his interactionist views concerning the mind-body problem: a universe with these features conflicts with physicalism(r), with $1 \leq \mathrm{r} \leq 6$ and $\mathrm{N}=1$. Furthermore, Popper argued for the metaphysical, and hence unscientific, character of determinism; but physicalism(r) may be either deterministic or probabilistic, and these metaphysical theses are a part of current (conjectural) scientific knowledge, according to the above hierarchical view.

The key point, of course, is that for Popper the metaphysical theses of metaphysical research programmes are not a part of (conjectural) scientific knowledge. These unfalsifiable theses, for Popper, are upheld in the context of discovery, but not in the context of acceptance. According to the hierarchical view, by contrast, theses at levels 1 to 7 are an integral part of scientific knowledge, despite being untestable and metaphysical. Some of these theses are, indeed, more securely a part of knowledge than any testable physical theory, however well corroborated. ${ }^{15}$

Finally, Popper explicitly rejected the basic argument underpinning the hierarchical view. In (Popper, 1983, 67-71), he discusses "silly" rivals to accepted theories - disunified rivals of the kind indicated above - and comments: "Thus the belief that the duty of the methodologist is to account for the silliness of silly theories which fit the facts, and to give reasons for their a priori exclusion, is naïve: we should leave it to the scientists to struggle for their theories' (and their own) recognition and survival" (Popper, 1983, 70). But this ignores that the "silly" rivals in question satisfy Popper's own methodological rules, as spelled out in (Popper, 1959a), better than the accepted theories: these rivals are more falsifiable, not refuted (unlike the accepted 
theories), the excess content is corroborated, and some are strictly universal. All this holds, for example, if the accepted theory is taken to be $\mathrm{T}$ (Newtonian theory, classical electrodynamics or whatever) and the silly rival is taken to be $T+T_{1}+\ldots+T_{n}$, discussed in section 3 above. One can scarcely imagine a more decisive refutation of falsificationism. The sillier these silly theories are, the more severe is the refutation. If falsificationism failed to discriminate between a number of reasonably good rival theories even though physicists in practice regard one as the best, this might well be regarded as not too serious a failing. But falsificationism fails in a much more serious way than this; it actually favours and recommends a range of theories that are blatantly unacceptable and "silly", thus revealing a quite dreadful inadequacy in the view. To argue, as Popper does, that these silly theories, refuting instances of his methodology, do not matter and can be discounted, is all too close to a scientist arguing that evidence that refutes his theory, should be discounted, something which Popper would resoundingly condemn. The falsificationist stricture that scientists should not discount falsifying instances (especially systematic falsifying instances), ought to apply to methodologists as well!

Popper might invoke his requirement of simplicity, quoted above, to rule out these silly rivals, but then of course the argument, outlined above, leading remorselessly to the hierarchical view, kicks in.

My argument is not, of course, just that Popper blocked the approach to the hierarchical view with invalid arguments. It is, rather, that the hierarchical view succeeds in exemplifying Popper's most basic and finest ideas about science and natural philosophy. It does this more successfully than falsificationism. Popper holds that science at its best proceeds by means of bold conjecture subjected to sustained criticism and attempted refutation. What the above argument has shown is that this process breaks down unless severe restrictions are placed on the conjectures open to consideration - restrictions that go against empirical considerations. Such restrictions commit science to making unfalsifiable, metaphysical assumptions. This in turn requires - given Popper's basic idea - that science must make explicit and severely criticize these assumptions, from the standpoint, especially, of how fruitful they seem to be for scientific progress. In short, empirical testing requires metaphysical criticizing. The one cannot proceed rigorously (i.e. critically) without the other. The outcome is a much strengthened version of Popper's conception of natural philosophy. Metaphysics forms an integral part of (conjectural) scientific knowledge. The scientific search for explanation and understanding emerge as absolutely fundamental.

Popper's failure to arrive at the hierarchical view had adverse consequences for what he had to say about a number of related issues: metaphysical research programmes, scientific realism, quantum theory, science as the search for invariance, the incompleteness of physics in principle, and the mind-body problem. A few words, now, about each of these issues.

Metaphysical research programmes are discussed, without the term being used, in a number of places (Popper, 1990, 1-26; 1994, chapter 5; 1998, Essay 7; 1999, chapter 6;), and are discussed explicitly in at least three places (Popper, 1976, sections 33 and 37; 1983, section 23; 1982, sections 20-28). In the last place, Popper lists what he claims to be the ten most important, influential metaphysical research programmes in the in the history of physics: Parmenides's thesis that the universe is a homogeneous, unchanging sphere; atomism; the geometrization programme of Plato and others; Aristotle's conception of essential properties and potentialities; Renaissance physics of Kepler, Galileo and others; the clockwork theory of the universe of Descartes and others; the theory that the universe consists of forces (Newton, Leibniz, Kant, Boscovich); field theory, associated with Faraday and Maxwell; the idea of a unified field (Einstein and others); indeterministic theory of particles associated with Born's interpretation of quantum theory. Popper comments on these programmes as follows:

"Such research programmes are, generally speaking, indispensable for science, although their character is that of metaphysical or speculative physics rather than of scientific physics. 
Originally they were all metaphysical, in nearly every sense of the word (although some of them became scientific in time); they were vast generalizations, based upon various intuitive ideas, most of which now strike us as mistaken. They were unifying pictures of the world - the real world. They were highly speculative; and they were, originally, non-testable. Indeed they may all be said to have been more of the nature of myths, or of dreams, than of science. But they helped to give science its problems, its purposes, and its inspiration" (Popper, 1982, 165).

These ten research programmes can be regarded as historically important versions of the hierarchical view, with levels 1 to 6 suppressed. Except that, rather surprisingly, Popper does not, here, characterize the research programmes as being made of three levels: basic metaphysical idea (plus associated methods), testable theory, observational and experimental results. Popper stresses that metaphysical theories, even though not testable, can nevertheless be rationally assessed in terms of their capacity to solve problems, the fruitfulness for science being the "decisive" issue. Popper also stresses (in line with the hierarchical view) that the search for unity is fundamental to science, to the extent even of declaring "the fundamental idea of a unified field theory seems to me one that cannot be given up - unless, indeed, some alternative unified theory should be proposed and should lead to success" (Popper, 1982, 194).

But, despite being "indispensable for science", and despite helping "to give science its problems, its purposes, and its inspiration", these "unifying pictures of the world" are "more of the nature of myths, or of dreams, than of science". Popper's conception of metaphysical research programme overlaps with, but also sharply diverges from, the hierarchical view of physics I have indicated above (see also Maxwell, 1998, chs 3-5; 2004a, chs, 1-2 and appendix). The scientific status of metaphysics is quite different. And Popper's conception lacks the hierarchy of the hierarchical view, and thus lacks the explicit common framework within which competing metaphysical research programmes, of the kind considered by Popper, may be rationally developed and assessed. (The metaphysical theses Popper considers are mostly level 7 ideas, as far as the above hierarchical view is concerned.)

Popper goes on to sketch his own proposal for an eleventh metaphysical research programme: the universe consists of a unified propensity field (Popper, 1982, 192-211; see also 1990, 1-26). Popper argues that this incorporates elements from all ten programmes he has discussed. It emerges from Popper's propensity interpretation of quantum theory, to which I now turn.

\section{Quantum Theory}

In The Logic of Scientific Discovery (first published in German in 1934) Popper made an important, though often overlooked, contribution to the interpretation of quantum theory. $\mathrm{He}$ refuted decisively the oft repeated interpretation of Heisenberg's uncertainty relations which holds that they prohibit the simultaneous precise measurement of position and momentum (and of some other pairs of quantum "observables"). Popper argues that it is vital to distinguish selection and measurement. A selection is some procedure which, for example, screens off "from a stream of particles, all except those which pass through a narrow aperture $\Delta x$ " (Popper, 1959a, 225-6). A measurement is some procedure which determines the value of some quantum variable or "observable" such as position, momentum or energy. And Popper goes on to point out that, whereas a selection can be used as a measurement, the reverse is in general not the case. We may use a Geiger counter to measure positions of electrons, but this does not provide a position selection.

The distinction that Popper has in mind here was further clarified by Margenau $(1958,1963)$, who used the term preparation rather than selection. A preparation is some physical proceduresome combination of screens with slits in them, magnetic fields, etc. - which has the consequence that if a particle exists (or is found) in some predetermined region of space then it will have (or will have had) a definite quantum state. A measurement, by contrast, actually detects a particle, and does so in such a way that a value can be assigned to some quantum 
"observable" (position, momentum, energy, spin, etc.). And Margenau strongly reinforces Popper's point that a measurement need not be a preparation. Measurements of photons, for example, far from preparing the photons to be in some quantum state, usually destroy the photons measured! On the other hand, a preparation is not in itself a measurement, because it does not detect what is prepared. It can be converted into a measurement by a subsequent detection. ${ }^{16}$ Margenau paid tribute to Popper's contribution: see Margenau $(1974,757)$.

Popper (1959a, 223-36) goes on to argue that Heisenberg's uncertainty relations place a restriction on what can be simultaneously selected (or prepared), but not on what can be simultaneously measured. Consider a stream of electrons moving in a horizontal direction only, with a definite momentum, there being zero motion in other directions. If now the electrons encounter a screen with a narrow horizontal slit in it of width $\Delta \mathrm{x}$, the electrons which pass through the slit will be scattered, up and down. They will acquire a velocity, a momentum, in the vertical direction, up or down. Heisenberg's uncertainty relations prohibit the selection of electrons so that the outcome is electrons with both a precise vertical position, and a precise vertical momentum. Furthermore, the smaller the slit $\Delta \mathrm{x}$ is, so the greater the resulting scatter will be, the greater the uncertainty in the resulting momentum of the electrons in the vertical direction. But none of this, Popper points out, prohibits the subsequent simultaneous measurement of position and momentum to any degree of accuracy. We may measure position subsequently, by means of a photographic plate for example, and quantum theory places no restrictions on the accuracy of this measurement of position. But this is, simultaneously, a measurement of vertical momentum. From the position measurement, the distance between the two screens, the location of the slit in the first screen, and knowledge of the horizontal momentum of the electrons, we can deduce what the vertical momentum of each detected electron is. The more precise we make the position measurements, so the more precise becomes the simultaneous momentum measurement, and Heisenberg's uncertainty relations place no restrictions whatsoever on how precise these simultaneous measurements of position and momentum can be. The position measurements at the photographic plate which detect electrons simultaneously measure the momentum of the electrons in the vertical direction, and these measurements may be made as precise as we please by placing the photographic plate further and further away from the screen with the slit in it.

Popper (1959a, 230-1) then argues, very effectively, that we need to be able to measure position and momentum simultaneously to a degree of accuracy well within Heisenberg's uncertainty relations in order to test experimentally the scatter predicted by those relations. This, to my mind, is the killer blow to the sloppy, customary interpretation of Heisenberg's uncertainty relations as prohibiting precise simultaneous measurement of position and momentum. ${ }^{17}$

The distinction, made by Popper in 1934, between selection and measurement, and subsequently elaborated by Margenau, is essential for a clear formulation of orthodox quantum theory, and ought to be an absolutely standard part of any introductory textbook on the subject. It is of far greater importance than Bohr's endlessly parroted idea that wave and particle are complementary, not contradictory, pictures of quantum systems. Whereas the former clarifies the theory, the latter merely obfuscates. Unfortunately, one can still find textbooks ignoring the former and solemnly expounding the latter.

I turn now to Popper's response to what is, in my view, the fundamental, and still unsolved, problem confronting quantum theory: the wave/particle dilemma. Quantum entities, such as electrons and atoms, seem to be both wave-like and particle-like, as revealed in the famous twoslit experiment. How can one have a sensible theory about the quantum domain when the basic entities of this domain seem to have such blatantly contradictory properties?

Orthodox quantum theory (OQT) evades this fundamental problem by being a theory merely about the results of performing measurements on quantum entities. Popper, appalled by the lack 
of realism of OQT (and even more appalled by the appeal, on some views, to "the Observer"), developed his propensity idea in the hope that it would provide a probabilistic and realistic interpretation of quantum theory (QT): see Popper (1957; 1959b; 1982; 1983, part II, ch. III). Popper expounded his propensity idea as providing an interpretation of probability theory, but in my view it is best understood as a new kind of dispositional (or necessitating) physical property, like hardness, elasticity, mass or charge in that it determines how entities interact, but unlike these in determining how entities with propensities interact probabilistically. ${ }^{18}$ The unbiasedness of a die is an example of a propensity: it causes the die, when tossed onto a smooth table, to land with one or other face up with probability $=1 / 6$. Popper conceives of this as a relational property between die and table (and manner of tossing).

Quantum entities, similarly, can, according to Popper, be regarded as having propensities to interact probabilistically with measuring instruments, in accordance with the predictions of QT. QT can be interpreted as a theory which specifies what these quantum propensities are, and how they change. Electrons and atoms are, for Popper, particles with quantum propensities - nonclassical relational properties between these entities and measuring instruments. The big difference between the die and the electron is that whereas the probabilistic outcomes of tossing the die are due to probabilistic variations in initial conditions (propensities being eliminable), in the case of the electron this is presumed not to be the case. Dynamical laws governing electrons are presumed to be fundamentally probabilistic, and not reducible to, or explainable in terms of, more fundamental deterministic laws. The apparent wave-like aspect of electrons is not physically real, but contains probabilistic information about an ensemble of similarly prepared, thoroughly particle-like electrons subjected to certain kinds of measurement. This idea receives support from the fact that the wave-like aspects of electrons are only detected experimentally via the wave-like distribution of a great number of particle-like detections, such as dots on a photographic plate.

Popper's key idea is that, in order to rid OQT of its defects, we need to take seriously the fundamentally probabilistic character of the quantum domain. ${ }^{19}$ This idea seems to me to be of great importance, and still not properly appreciated by most theoretical physicists even today. But some of Popper's more specific suggestions are unsatisfactory. Popper's propensity interpretation of QT has been criticized for being just as dependent on measurement, and thus on classical physics, as OQT: see (Feyerabend, 1968). Popper replied that the propensity of the electron refers, not just to measuring instruments, but to "any physical situation" (Popper, 1982, $71, \mathrm{n} 63)$.

But this response is unsatisfactory in two respects. First, the "physical situations" in question are not specified, and secondly, there is no indication as to how they can be specified in simple, fundamental, and purely quantum mechanical terms. The first failure means that Popper's propensity version of QT is either about quantum entities interacting with measuring instruments and thus at best a clarification of Bohr's OQT, or it is almost entirely open and unformulated (in view of the failure to specify the relevant "physical situations"). The second failure means that Popper's propensity version of quantum theory could not be an exclusively micro-realistic theory, exclusively about micro systems, in the first instance. Rather, it would be what may be called a micro-macro realistic theory, in that it would be about micro systems (such as electrons) interacting with macro systems, relevant macro "physical situations" with propensities not reducible to the propensities of micro systems. ${ }^{20}$ This second failure means that the kind of theory Popper envisages would be as disunified as OQT: some laws apply only to macro systems, and cannot be derived from laws that apply to micro systems. (This defect can only be overcome if QT can be interpreted as attributing propensities exclusively, in the first instance, to micro-systems: but it is just this which Popper rejects.)

The crucial issue, which Popper fails to confront, is simply this: what precisely are the physical conditions for probabilistic transitions to occur, what are the possible outcomes, and 
what probabilities do these possible outcomes have? During the course of expounding his eleventh, unified propensity field research programme, Popper does say "It is the interaction of particles - including photons - that is indeterministic, and especially the interaction between particles and particle structures such as screens, slits, grids, or crystals . . . a particle approaching a polarizer has a certain propensity to pass it, and a complementary propensity not to pass it. (It is the whole arrangement which determines these propensities, of course.) There is no need to attribute this indeterminism to a lack of definiteness or sharpness of the state of the particle" (Popper, 1982, 190).

The trouble with what Popper says here is that endless experiments have been performed with interacting particles, and with particles interacting with "screens, slits, grids, or crystals", which seem to reveal that quantum entities do not interact probabilistically, and do seem to be smeared out spatially in a way that is entirely at odds with these entities being particles. The classic example of this is the two-slit experiment: the interference pattern that is the outcome (detected via a great number of particle-like detections) can be explained if it is assumed that each electron interacts with the two-slitted screen deterministically as a wave-like entity that goes through both slits, and then collapses, probabilistically, to a small region when it subsequently encounters the detecting photographic plate. But if the electron is a particle, and goes through just one slit, it is all but impossible to see how it can interact probabilistically with the screen in such a way as to mimic wave interference, "knowing" somehow that the other slit is open.

Popper at this point appeals to Landé (1965) who in turn appeals to Ehrenfest and Epstein's (1927) attempted explanation of the two-slit experiment, based on an idea of Duane (1923). Duane's idea is that the two-slitted screen can only take up momentum in discrete amounts, and hence the electron can only be scattered by discrete amounts. But Ehrenfest and Epstein, in their original paper, admit that this attempted explanation is not successful. They conclude their paper with the words "It is, therefore, clear that the phenomena of the Fresnel diffraction cannot be explained by purely corpuscular considerations. It is necessary to attribute to the light quanta properties of phase and coherence similar to those of the waves of the classical theory" (Ehrenfest and Epstein, 1927). Duane, and Ehrenfest and Epstein, considered X-ray diffraction but their conclusions apply to the diffraction of electrons as well. There is, of course, Bohm's (1952) interpretation of quantum theory, which holds electrons to be particles with precise trajectories; but Bohm's theory is deterministic and, in addition to particles, postulates the quantum potential, a kind of wave-like entity which guides the flight of the electron (all very different from Popper's propensity idea).

In order to implement Popper's idea properly, in my view, we need to take the following steps. First, we should seek to develop a fully micro-realistic version of quantum theory which attributes propensities to micro systems - to electrons, photons, etc. - and specifies precisely how these entities interact with one another probabilistically entirely in the absence of macro "physical situations" or measuring instruments. Second, we need to recognize that quantum entities, possessing quantum propensities as basic properties, will be quite different from any physical entity associated with deterministic classical physics. It is unreasonable to suppose that quantum entities are anything like classical particles, waves or fields. Third, we need to specify precisely, in quantum theoretic terms, what the conditions are for probabilistic transitions to occur, what the possible outcomes are, and what their probabilities are. Probabilistic transitions may occur continuously, or intermittently, in time. If we adopt the latter option (which is what QT suggests), we should not be surprised if quantum entities turn out to be such that they become deterministically "smeared out" spatially with the passage of time, until a probabilistic transition provokes an instantaneous localization. Elsewhere I have developed Popper's propensity idea in this direction, the outcome being a fully micro realistic propensity version of QT which is, in principle, experimentally distinguishable from OQT: see (Maxwell, 1976b; 
1982; 1988; 1994; 1998, ch. 7; 2004b; 2011c). According to this version of QT, probabilistic transitions are associated with the creation of new "particles" or bound systems.

Popper argued for scientific realism tirelessly and passionately. Natural philosophy is hardly conceivable without realism, in that it springs from the desire to know and to understand the ultimate nature of the cosmos. Realism is required for explanation. A physical theory is only explanatory if the dynamical laws it specifies are invariant throughout the range of phenomena to which the theory applies. At the level of observable phenomena there is incredible diversity: only by probing down to the level of unobservable phenomena can invariance be discovered (as when quantum theory and the theory of atomic structure disclose invariance throughout the incredible diversity of phenomena associated with chemistry and properties of matter). But, despite his passionate advocacy of scientific realism and the search for invariance, Popper also, at a certain point, turns about and opposes the whole direction of the argument. Popper supports scientific realism but not, as we have seen in connection with quantum theory, micro-realism. He holds that the "fundamental idea" of some kind of "unified field theory . . . cannot be given up" (Popper, 1982, 194) and argues for theoretical physics as the search for invariance in nature (Popper, 1998, ch. 7), but then argues that invariance has its limitations, the physical universe is not closed, physicalism deserves to be rejected, there is emergence of new physical properties not explainable even in principle in terms of the physical properties of fundamental physical entities, macro systems having physical properties not wholly explicable in terms of the properties of constituents, there being "downward causation": see for example (Popper, 1972, chs. 3, 4, 6 and 8; 1982; 1998, ch. 7; Popper and Eccles, 1977, Part I). From the standpoint of the hierarchical view, all this is scientific heresy. It involves rejecting theses at levels 4 to $9-$ the most scientifically fruitful metaphysical conjectures we possess.

\section{The Physical Universe and the Human World}

How is Popper's ambiguous attitude to what may be called the scientific picture of the world to be understood? Popper is responding to what might be called the "double aspect" of modern natural philosophy. On the one hand, it provides us with this magnificent vision of the universe: the big bang, cosmic evolution, formation of galaxies and stars, creation of matter in supernovae, black holes, the mysteries of quantum theory, the evolution of life on earth. On the other hand, the implications of this vision are grim. If everything is made up of some kind of unified selfinteracting field - everything being governed by some yet-to-be-discovered true theory of everything - what becomes of the meaning and value of human life, human freedom, consciousness, everything we hold to be precious in life? Science gives us this awe-inspiring vision and immense power on the one hand, and then takes it all away again by revealing us to be no more than a minute integral part of the physical universe, wholly governed by impersonal physical law in everything we think and do.

Popper believes that if the above picture of the world is correct, and some yet-to-bediscovered physical theory (whether deterministic or probabilistic) is true, the physical universe being closed, then everything that gives value to human life cannot exist (or perhaps could only be an illusion). Human freedom, creativity, great art and science, the meaning and value of human life, even consciousness itself, would be impossible. There are, then, for Popper, powerful reasons for rejecting physicalism (with $r=4$ to 7 ). It is metaphysical, not scientific. It is refuted by the obvious fact that theoretical scientific knowledge, not itself a part of the physical universe, can have an impact on the physical world. An obvious example is the explosion of the atomic bombs in Nagasaki and Hiroshima. These terrible physical events could not have occurred without the prior discovery of relevant physical theory. Thus Popper develops his interactionist approach to the mind/body problem: the world of theories, problems and arguments (world 3) interacts with the physical world (world 1) via human consciousness (world 2). The physical universe is open to being influenced by inventions of the human mind. There is 
emergence and downward causation, and propensities are to be associated with macro physical systems that cannot be reduced to the properties of constituent micro systems.

But all this needs to be contested. Physicalism is scientific. It is a part of (conjectural) scientific knowledge, as the hierarchical view makes clear. The scientific view is that the physical universe is causally closed. But this does not mean that physics is all that there is. Physics is concerned only with a highly specific aspect of all that there is: it may be called the "causally efficacious" aspect, that which everything has in common with everything else and which determines (perhaps probabilistically) the way events unfold. Sensory qualities, experiences, feelings and desires, consciousness, meaning and value, all exist and are nonphysical. Reductionism (the thesis that everything can be reduced to, or fully explained in terms of, the physical) is false, even though the physical universe is causally closed. As for Popper's argument that atomic explosions establish that world 3 theories can influence world 1 events, it is invalid.

What we need to recognize is that things can be explained and understood in (at least) two very different ways. On the one hand, there are physical explanations. And on the other, there are what I have called elsewhere personalistic explanations - explanations of the actions of people in terms of intentions, beliefs, knowledge, desires, plans, feelings and so on, including the content of these things, the possible facts or states of affairs to which they refer.

A beautiful illustration of this distinction between physical and personalistic explanations is to be found in Plato's Phaedo. Socrates is in prison awaiting death. Commenting on his disappointment that Anaxagoras had nothing to say about the purposes or reasons underlying the world order, Socrates remarks:-

"It was as if somebody would first say that Socrates acts with reason or intelligence; and then, in trying to explain the causes of what I am doing now, should assert that I am now sitting here because my body is composed of bones and sinews; $\ldots$ and that the sinews, by relaxing and contracting, make me bend my limbs now, and that this is the cause of my sitting here with my legs bent ... Yet the real causes of my sitting here in prison are that the Athenians have decided to condemn me, and that I have decided that ... it is more just if I stay here and undergo the penalty they have imposed on me. For, by the Dog, ... these bones of mine would have been in Megara or Boetia long ago ... had I not thought it better and nobler to endure any penalty my city may inflict on me, rather than to escape, and to run away."

This passage is quoted by Popper (Popper and Eccles, 1977, 171) to indicate the distinction between a physical explanation and an explanation in terms of "intentions, aims, ends, motives, reason and values to be realized" (Popper and Eccles, 1977, 171) - what I am calling here a personalistic explanation. Popper assumes, in effect, that if physicalism is true, the physical universe is closed, and a physical explanation of Socrates' movements in principle exists, then no personalistic explanation of why Socrates remains in prison can be viable. But what this overlooks is a view that I, and others, have defended according to which personalistic explanations may have real content and force even though physicalism is true. According to this anti-reductionist version of physicalism, personalistic explanations are compatible with, but not reducible to, physical explanations. This is a view that I have developed over a number of years: see Maxwell (1966 ); (1968a ); (1968b ); (1984 ), pp. 171-89 and chapter 10; and especially ( 2000 ); ( 2001 ); ( 2009 ); (2010 ); (2011a ). For related ideas, see Taylor (1964 ), Dennett (1971; $1984 ; 1989)$, Nagel (1986) and Chalmers (1996 ).

It is almost a miracle that people (and animals by extension) should be amenable to these two kinds of explanation simultaneously. This miracle is to be understood by an appeal to history, to evolution, and to Darwin's theory of evolution. ${ }^{21}$ If a purely physical explanation of an atomic 
explosion is in principle (not of course in practice) possible, it would explain merely by showing how one (highly complex) physical state of affairs follows from a prior state in accordance with fundamental physical laws. It would leave out what the personalistic explanation can render intelligible, namely what prior intentions, plans, knowledge, human actions led up to manufacturing and exploding the bomb. The physical explanation would describe all this physically, but with the experiential, personalistic aspect left out.

Popper's arguments may be valid when directed against the versions of physicalism he considers: radical physicalism or behaviourism, panpsychism, epiphenomenalism, and the identity theory of U. T. Place and J. J. C. Smart (Popper and Eccles, 1977, ch. P3). But they are not valid when directed against the anti-reductionist version of physicalism just indicated. No longer is it possible to argue that physicalism is not viable because it cannot explain the role that scientific discoveries can have in helping to bring about subsequent events, such as atomic explosions. Anti-reductionist physicalism makes it possible to explain such events personalistically, a kind of explanation that is fully viable, even though physicalism is true, essentially because it is compatible with, but not reducible to, physical explanations.

Popper's three worlds, interactionist view may be thought to be, in some respects, heroic, in that it is very much at odds, as I have tried to indicate, with the scientific picture of the world. Interactionism amounts to postulating that tiny, poltergeist-like events occur persistently in our brains. It is a part of Popper's creed, of course, that the philosopher should swim against the tide of fashion, and should put forward bold conjectures that challenge current dogmas. All this is admirable.

What is less admirable, perhaps, is the way in which Popper ignored that anti-reductionist version of physicalism, indicated above, which constitutes a counterexample to his whole argument - the version of physicalism which holds that the physical universe, though closed causally, is not closed explanatorily, in that non-physical, experiential features of people and things exist and can be explained and understood personalistically, a mode of explanation compatible with, but not reducible to, physics. Personalistic explanations refer to the nonlinguistic content of beliefs, conjectures and so on, to possible facts or states of affairs, in other words. These contents stand in for Popper's world 3 "theories" or "propositions", but have none of the highly problematic, objectionable features of Popper's world 3 entities.

In order to see how this kind of view can do what Popper claims for his three world view without employing anything like his quasi-Platonic, poltergeistic world 3 entities, consider the central candidate for a world 3 entity - the proposition. This can be regarded as a useful fiction. Beginning with unproblematic utterances and facts, we can arrive at propositions in the following six steps.

First, we consider not just facts, but also possible facts, possible states of affairs, including non-existent facts, ostensible facts asserted by false statements. We pretend that possible facts exist - though of course those that correspond to false statements do not.

Second, we consider all utterances, however spoken or written, that are utterances of one and the same sentence - "snow is white" for example, or "Die Frau ist schön". Even though a great variety of different sounds or marks on paper are made, we can nevertheless say that one and the same sentence is uttered or written down, just as long as these different sounds or marks do indeed correspond to the same sentence - the English sentence "snow is white" let us say. Even if a person merely thinks the sentence, we can still say it is this sentence that is thought.

Third, in a way that is closely analogous to the above, we can consider all declarative sentences, or statements, in whatever form or language they may come, that assert the same possible fact, possible state of affairs, and declare that all these are the same proposition. Even though a great variety of different sentences (or strings of sentences) are, on different occasions, uttered, written down or thought by different people - in the same language or in different languages - nevertheless we declare these people to be asserting, or thinking, the same 
proposition. And just as many different noises or marks can be the same sentence without this meaning that the sentence is itself somehow an extra-linguistic (world 3) entity, distinct from its many actual expressions, so too the fact that the assertion of many different sentences on different occasions can all be the assertion of the same proposition does not mean that the proposition is some extra-linguistic (world 3) entity distinct from its many assertions on many different occasions by means of different sentences.

Fourth, we now imagine that propositions are precise and unambiguous in the sense that, given any proposition, there corresponds, unambiguously, a definite possible fact or state affairs, asserted by the proposition, which must obtain if the proposition is to be true.

Fifth, we consider not just propositions that are in fact asserted or considered by someone on some occasion but, in addition, propositions, corresponding to some possible state of affairs, which could be asserted or considered.

Sixth, and finally, we consider, in addition, propositions - corresponding to possible states of affairs - that could never be uttered by anyone, because there are infinitely many of them (the consequences of a theory perhaps) or because it would take infinitely long to state just one such proposition.

As a result of taking these six steps, we have arrived at fictional entities, propositions, which do not exist but which it is very useful to pretend do exist. Propositions, in this sense, stand in for Popper's disembodied, poltergeistic, world 3 intellectual entities. Personalistic explanations of human actions, including those that refer to scientific theories being used to create new technology, can refer to propositions in the sense indicated.

It might be objected that personalistic explanations, interpreted in this way, appeal to fictional entities, to entities that do not exist. These explanations are therefore false, and thus not viable. I have four replies to this objection. First, many viable scientific explanations are false - in that they employ false scientific theories. Being false is not sufficient to render an explanation unviable. Second, those personalistic explanations which explicitly formulate the propositions employed in the explanation thereby ensure that these propositions do exist, as linguistically formulated statements. Third, personalistic explanations need, in the main, to refer to and use the content of propositions, rather than the propositions themselves - what the propositions assert to be the case, in other words. The content of a proposition may be perfectly real, even though the proposition itself is a fictional entity, and thus something which does not exist in its own right. Fourth, many clearly viable personalistic explanations refer to the content of false beliefs. That there are no facts corresponding to these (false) beliefs does not render the explanations invalid.

Einstein once remarked "Knowledge exists in two forms - lifeless, stored in books, and alive in the consciousness of men. The second form of existence is after all the essential one; the first, indispensable as it may be, occupies only an inferior position" (Einstein, 1973, 80). This, in my view, does better justice to what really matters than Popper's emphasis on "objective knowledge" and "epistemology without a knowing subject" (Popper, 1972, chs. 3 and 4).

\section{The Significance of Natural Philosophy for Education}

I conclude with a few words about the educational significance of natural philosophy.

Many scientists, and science teachers, regret the current "flight from science" - the increasing tendency of young people today to choose subjects to study other than science. A number of remedies are tried, from science festivals to participatory science education. But there is one possible source for this current loss of interest in science that tends to be overlooked: pupils and students are given no opportunity to do natural philosophy.

Why is the sky blue? Where does rain come from? Why does the sun, every day, rise in the east, travel across the sky, and sink in the west? Why does the moon shine? And why the sun? What is everything made up of? How does space end? Where did everything come from, and 
how will everything end? How did people come into existence? What about animals, and plants? How do we see the world around us? What happens in our heads when we talk to ourselves silently, picture places we have visited, or think $?^{22}$

Every child, and every student, from five years onwards, should get the opportunity to ask, and to try to answer, questions such as these. They should get the opportunity to hear what their contemporaries think about these questions, and how one might go about choosing between different answers. When pupils have become actively engaged in pursuing natural philosophy, the suggestions of others can be introduced into the discussion. Democritus, Galileo, Newton, Faraday, Darwin can be introduced, not as authorities, but as fellow natural philosophers whose ideas deserve to be treated on their merits. Science, encountered in this way, as an opportunity to do natural philosophy, might gradually become what it ought to be, a vital part of our general culture.

The hope behind getting children to engage in natural philosophy is not, of course, that they will rediscover for themselves the path of modern science. The idea, rather, is that it is only if one has oneself struggled with a problem that one is in a position fully to enjoy, appreciate, understand and rationally assess the vastly superior attempted solutions of others. All too often science education amounts to indoctrination, in that one is informed of solutions without even being informed of what the problems were that led to the solutions, let alone being given an opportunity to think about the problems for oneself in the first place. Despite the influence that Popper's ideas have had on science education, it is still the case that science is taught as the acquisition of information and skills, rather than being what it ought to be, an opportunity to do natural philosophy.

\section{References}

Bohm, D. 1952. A Suggested Interpretation of the Quantum Theory in Terms of "Hidden" Variables. Physical Review 48: 166-79 and 180-93.

Chalmers, D. 1996. The Conscious Mind. Oxford: Oxford University Press.

Dennett, D. 1971. Intentional Systems. Journal of Philosophy LXVIII: 87-106. 1984. Elbow Room. Oxford: Oxford University Press. 1989. The Intentional Stance. Cambridge, Mass.: M. I. T. Press.

Duane, W. 1923. Proc. Nat. Acad. Sci. Wash. 9: 158.

Ehrenfest, P. and P. Epstein 1927 Proc. Nat. Acad. Sci. Wash. 13: 400.

Einstein, A., 1949. Autobiographical Notes. In Albert Einstein: Philosopher-Scientist, ed. P. A. Schilpp. La Salle, Ill: Open Court: 1-94.

1973. Ideas and Opinions. London: Souvenir Press.

Feyerabend, P., 1968. On a Recent Critique of Complementarity. Philosophy of Science 35: 309-31 and 36: 82-105 (1969).

Feynman, R. P. et al., 1965. The Feynman Lectures on Physics. Reading, Massachusetts: Addison-Wesley.

Heisenberg, W., 1930. The Physical Principles of Quantum Theory. Chicago:

Isham, C. J. 1997. Structural Issues in Quantum Gravity. General Relativity and Gravitation GR 14. Singapore: World Scientific, 167-209.

Kuhn, T. S. 1970. The Structure of Scientific Revolutions. Chicago: Chicago University Press.

Landé, A. 1965. New Foundations of Quantum Mechanics. Cambridge: Cambridge University Press.

Margenau, H. 1958. Philosophical Problems concerning the Meaning of Measurement in Physics. Philosophy of Science 25: 23-33.

1963. Measurements and Quantum States: Part I. Philosophy of Science 30: 1-16. 1974. On Popper's Philosophy of Science. In Schilpp (1974): 750-9. 
Maxwell, N. 1966. Physics and Common Sense. British Journal for the Philosophy of Science 16:,295-311.

1968a. Can there be Necessary Connections between Successive Events?, British

Journal for the Philosophy of Science 19: 1-25.

1968b. Understanding Sensations. Australasian Journal of Philosophy 46: 127-46

1974. The Rationality of Scientific Discovery. Philosophy of Science 41: 123-53 and

247-95.

1976a. What's Wrong With Science? Frome, England: Bran's Head Books.

1976b. Toward a Micro Realistic Version of Quantum Mechanics. Foundations of

Physics 6: 275-92 and 661-76.

1982. Instead of Particles and Fields. Foundations of Physics 12: 607-31.

1988. Quantum Propensiton Theory: A Testable Resolution of the Wave/ Particle

Dilemma, British Journal for the Philosophy of Science 39: 1-50.

1993. Induction and Scientific Realism. British Journal for the Philosophy of Science

44: 61-79, 81-101 and 275-305.

1994. Particle Creation as the Quantum Condition for Probabilistic Events to Occur,

Physics Letters A 187: 351-5.

1998. The Comprehensibility of the Universe. Oxford: Oxford University Press.

2001. The Human World in the Physical Universe: Consciousness, Free Will and

Evolution. Lanham, Maryland: Rowman and Littlefield.

2002. The Need for a Revolution in the Philosophy of Science. Journal for General

Philosophy of Science 33: 381-408.

2004a. Is Science Neurotic? London: Imperial College Press.

2004b. Does Probabilism Solve the Great Quantum Mystery? Theoria, 19/3: 321-36.

2004c. Scientific Metaphysics. http://philsci-archive.pitt.edu/archive/ 00001674/

2005. Popper, Kuhn, Lakatos and Aim-Oriented Empiricism. Philosophia 32: 181-

239.

2007. From Knowledge to Wisdom: A Revolution for Science and the Humanities, $2^{\text {nd }}$

ed. London: Pentire Press.

2008. Do We Need a Scientific Revolution? Journal of Biological Physics and

Chemistry, vol. 8/3.

2009. ' How Can Life of Value Best Flourish in the Real World?', in Science and the

Pursuit of Wisdom: Studies in the Philosophy of Nicholas Maxwell, edited by Leemon

McHenry, Frankfurt : Ontos Verlag, pp. 1-56.

2010. Cutting God in Half-And Putting the Pieces Together Again: A New Approach

to Philosophy. London : Pentire Press .

2011a. 'Three Philosophical Problems about Consciousness and their Possible

Resolution', Open Journal of Philosophy 1, no. 1, 1 - 10 .

2011b. 'A Priori Conjectural Knowledge in Physics', in What Place for the A Priori?

ed. Michael Shaffer and Michael Veber . Chicago : Open Court , pp. 211-40 .

2011c. ' Is the Quantum World Composed of Propensitons?', in Probabilities, Causes

and Propensities in Physics, ed. Mauricio Suárez, Synthese Library, Dordrecht : Springer,

pp. $221-43$.

2013. 'Has Science Established That the Cosmos Is Physically Comprehensible?',

Recent Advances in Cosmology, A . Travena and B. Soen (eds.), New York : Nova

Publishers Inc ., pp. 1 - 56 (available online at http://discovery.ucl.ac.uk/1369638/). forthcoming. In Praise of Natural Philosophy.

Nagel, T. 1986. The View from Nowhere. Oxford: Oxford University Press.

Penrose, R., 2004, The Road to Reality. London: Jonathan Cape. 
Popper, K. R. 1957. The Propensity Interpretation of the Calculus of Probability, and the Quantum Theory. Observation and Interpretation, ed. S. Körner and M. Pryce. London: Butterworths: 65-70 and 88-9. 1959a. The Logic of Scientific Discovery. London: Hutchinson. 1959b. The Propensity Interpretation of Probability. British Journal for the Philosophy of Science, 10: 25-42.

1963. Conjectures and Refutations. London: Routledge and Kegan Paul.

1972. Objective Knowledge. Oxford: Oxford University Press.

1974. Replies to My Critics. In Schilpp (1974), 961-1197.

1976. Unended Quest. London: Fontana.

1982. Quantum Theory and the Schism in Physics. London: Hutchinson.

1983. Realism and the Aim of Science. London: Hutchinson.

1990. A World of Propensities. Bristol: Thoemmes.

1994. The Myth of the Framework. London: Routledge.

1998. The World of Parmenides. London: Routledge.

1999. All Life is Problem Solving. London: Routledge.

Popper, K. R. and J. C. Eccles, 1977. The Self and Its Brain. London: Springer-Verlag.

Schilpp, P. A. 1974. The Philosophy of Karl Popper. La Salle, Illinois: Open Court.

Taylor, C. 1964. The Explanation of Behaviour. London: Routledge and Kegan Paul.

\section{Notes}

1. Is it really appropriate for me to use the phrase "natural philosophy" when it does not appear in the index of any of Popper's books, and Popper in relevant contexts in the main speaks of cosmology, or of great science? The problem with Popper's preferred term of "cosmology" is that it is misleading, in that cosmology is now a recognized scientific discipline, alongside theoretical physics, astronomy and astrophysics. "Natural philosophy" is much more appropriate, in that it alludes to natural philosophy as pursued by Galileo, Descartes, Hooke, Newton, Boyle, Leibniz and others of the $17^{\text {th }}$ century, which intermingled physics, mathematics, astronomy, philosophy, metaphysics, epistemology, methodology, and even theology. In any case, as Popper himself persistently reminds us, words do not matter. In at least one place, however, Popper does refer to natural philosophy. He writes: "It is the great task of the natural sciences and of natural philosophy to paint a coherent and understandable picture of the Universe. All science is cosmology, and all civilizations of which we have knowledge have tried to understand the world in which we live, including ourselves, and our own knowledge, as part of that world" (Popper, 1982, 1).

${ }^{2}$ See also (Popper, 1982, 172-3; 1983, 8; 1994, 109-10).

3 . But natural philosophy is not yet quite dead. For a great contemporary work of natural philosophy see Penrose (2004).

4. As we shall see, this attitude of Popper towards metaphysics did not really change, even later on in his life when he came to write about "metaphysical research programmes". Popper himself was quite explicit on this point: see, for example, Popper (1999, 76-7).

5. This needs to be amended to read "No disunified theory, not entailed by a true unified theory (possibly plus true initial conditions), is true". Unified theories entail endlessly many approximate disunified theories: the true, unified theory of everything (supposing it exists) will entail such true disunified theories as well.

6. I make no apology for suggesting improvements to Popper's philosophy. The highest compliment you can pay a philosopher is to suggest improvements to his work. It shows you take his problems, and his attempted solutions, seriously. The second highest compliment is to criticize. That shows that, even though you can't suggest improvements, you can at least suggest 
what those who seek improvements need to grapple with. Finally, merely to give an exposition of a philosopher's work is no compliment at all, but something close to an insult. It suggests the philosopher in question failed to make his thought clear. In the case of Popper, who was so supremely lucid, this would be the ultimate insult. Popper ought to have approved of the attempt to improve his ideas. He certainly thought progress in philosophy was desirable and possible - if only philosophers would abandon sterile meaning analysis, and instead learn from the way science makes progress, by proposing and critically assessing bold possible solutions to serious problems. 7. Popper puts forward two ways of comparing degrees of falsifiability of theories: by means of the "subclass relation" and by means of "dimensionality": see Popper (1959, chapter VI) for details. There are thus two theories of simplicity, corresponding to these two ways of comparing degrees of falsifiability. My refutation of Popper's identification of simplicity with falsifiability applies only to the subclass idea. It does not apply to the dimensionality idea. However Popper, quite properly, declares that if the two methods for comparing falsifiability clash then it is the subclass method which must be accepted (Popper, 1959, 130). In the case of $T$ and $\mathrm{T}+\mathrm{T}_{1}+\ldots+\mathrm{T}_{\mathrm{n}}$, the former will, in general, be more falsifiable, and thus simpler, than the latter, if compared by means of dimensionality, but the reverse is the case if the two theories are compared by means of the subclass relation. Thus, since the verdict of the subclass relation is to be accepted if the two clash, Popper's account of simplicity commits him to holding that $\mathrm{T}+\mathrm{T}_{1}+\ldots+\mathrm{T}_{\mathrm{n}}$ is simpler than $\mathrm{T}$.

8. In a fascinating essay, Popper discusses the view that "science is strictly limited to the search for invariants ... for what does not change during change" (Popper, 1998, ch. 7, 154). But Popper does not here propose that a physical theory is unified or simple if what it asserts is invariant throughout the range of phenomena to which it applies. In other words, invariance is not exploited as providing the solution to the problem of simplicity. And a major theme of the essay is to express reservations concerning the search for invariants. Thus he says "though the search for invariants is admittedly one of the most important of all scientific tasks, it does not constitute or determine the limits of rationality, or of the scientific enterprise" (Popper, 1998, 154).

9. This simplifies what I have spelled out elsewhere. In Maxwell (1998 and 2004a) I distinguish eight, rather than just five, kinds of disunity.

10. I have sketched an account of what it is for a theory to be unified, but have not said anything about simplicity. For that, see Maxwell (1998, chapter 4, section 16; 2004a, 172-4). It is a great success of the theory that it sharply distinguishes the two notions of unity and simplicity. 11. What is depicted in the diagram is a specific version of a view - elsewhere called "aimoriented empiricism" - that I have developed over a number of years, some versions being more elaborate than others: see Maxwell (1974; 1976a; 1984; 1993; 1998; 2002; 2004a; 2004c; 2005). The view arose as a modification of Popper's falsificationism, made to make explicit, and so criticizable, within the context of science, metaphysical assumptions implicit in the methods of science - assumptions which falsificationism does not, and cannot, acknowledge.

12. Elsewhere I have suggested that physics today should accept, as its level 7 thesis, a doctrine I have called "Lagrangianism". This asserts that the universe is such that all phenomena evolve in accordance with Hamilton's principle of least action, formulated in terms of some unified Lagrangian (or Lagrangian density): for further details see (Maxwell, 1998, 88-9 and 175-6) and references given therein. There are hints, however, in modern physics that Lagrangianism may need to be rejected: see Maxwell (1998, 89) and Isham (1997, 94-5).

13. Popper (1959a, 61-2 and 252-3) recognized that metaphysical theses have methodological counterparts and argued, in some cases, for the adoption of the counterparts. What Popper did not appreciate is that the argument works the other way round as well: where a methodological rule has a metaphysical counterpart, the metaphysical thesis needs to be made explicit within 
science so that it can be criticized and improved, this in turn enabling us to improve the counterpart methodological rule.

14. It may be, of course, that even the top level 1 thesis is false. This possibility is taken into account by more general versions of the hierarchical view that I have formulated and argued for elsewhere (Maxwell, 1998; 2004a; 2005), which take, as their top thesis, merely that the universe is such that we can acquire some knowledge of our local circumstances. Whatever the universe is like, it can never facilitate the growth of knowledge to reject this thesis! The version of the hierarchical view, sketched here, can be construed to be embedded in one or other of the more general versions of the view.

15. This difference has major implications for scientific practice. The metaphysical theses of Popper's metaphysical research programmes, being adopted in the context of discovery only, can suggest specific research programmes within physics, but cannot determine what testable theories are accepted and rejected. By contrast, the metaphysical theses of the hierarchical view, being adopted as a part of scientific knowledge in the context of acceptance, constitute research guidelines for the whole physics, and help determine what testable theories are accepted and rejected (in addition to empirical considerations). The different status that metaphysical theses have, in the two views, means that these theses play substantially different roles in scientific practice.

16. The formalism of orthodox quantum theory seems to put quantum observables on the same footing. In fact, the observable position is fundamental. Measurement of other obervables, such as momentum, energy, spin, always involve a preparation - so that eigenstates corresponding to the observable in question can be associated with specific spatial regions - plus a detection, a position measurement, in one or other region. This combination of preparation and position measurement constitutes the measurement of the observable in question - momentum, spin or whatever. The point that all quantum measurements reduce to measurements of position is made by Feynman and Hibbs (1965, 96); for a discussion see Maxwell (1976, 661-3).

17. Popper recognizes, correctly, that Heisenberg (1930) holds that his uncertainty relations prohibit precise simultaneous measurement of position and momentum as far as the future is concerned, but not concerning the past. What Popper objects to is Heisenberg's view that when such simultaneous measurements are interpreted to be about the past, they are meaningless. 18. This is close to Popper's own view of the matter. Thus he says that the propensity view "allows us to interpret the probability of a singular event as a property of the singular event itself, to be measured by a conjectured potential or virtual statistical frequency rather than by an actual or by an observed frequency" (Popper, 1983, 359). In other words, Popper's propensity view can be regarded as a new application of the standard frequency interpretation of probability. 19. I may be overstating things a bit here. It is true that Popper does say in one place (Popper, 1982, 98-9) "if we do interpret quantum theory as a theory of physical propensities, then we can solve all those difficulties which have given rise to the Copenhagen interpretation". Earlier, however, Popper's view was that in order to rid OQT of its defects, we need to take seriously the fundamentally probabilistic character of quantum theory, leaving open the question of whether Nature herself is probabilistic or deterministic. Much of what Popper argued for, in connection with QT, is to be found in (Popper, 1959a) first published in 1934, when Popper supported determinism, long before the development of his propensity view (Popper, 1957; 1959b). Thus, his view that QT is a statistical theory of particles, solving statistical problems, his interpretation of Heisenberg's uncertainty relations as statistical scatter relations, his rejection of wave/particle duality, anti-realism and subjectivism - all these points are to be found in the 1934 edition of Popper (1959a). Even Popper's denial of the so-called "reduction of the wave packet" on measurement, as a real physical process, is independent of his propensity view. The chief 
function of the propensity view, it seems, is to clarify how the statistical theory of QT can apply to individual quantum systems and measurements.

20. David Miller's discussion of Popper's mature views about propensities would seem to indicate that Popper came to construe propensities quite generally in this micro-macro fashion: see Miller (this volume, pp. 12-15).

21. We require an appropriate version of Darwinism, however, one which gives a role to purpose and personalistic action in evolution, and holds that the mechanisms of evolution themselves evolve as evolution proceeds. In Maxwell ( 1984 , pp. 269-75) I outlined a version of Darwinism I called the generalized Darwinian research programme : this holds that all life is purposive, and seeks to help us to understand how purposive life has evolved in a purposeless universe, purposive action playing an increasingly important role in the mechanisms of evolution with the development of evolution by cultural means, biological evolution gradually becoming human history. In Maxwell ( 2001 ), chapter 7 I elaborate this version of Darwinism further, and suggest how it might help us to understand the evolution of human qualities we especially value, such as sentience, consciousness, language, personalistic understanding, science, art and free will. In Maxwell (2010), chapter 8 I distinguish nine different versions of Darwinism: the fi rst is purely mechanistic; subsequent versions give greater and greater roles to purposive action in evolution. I like to think that Popper would have approved - at least to some extent - given what he says about evolution in, for example, Popper ( 1994b ), chapter 3. Popper there stresses 'the leading role played in evolution by behaviour and by behavioural discoveries ... the development of new behavioural aims, preferences, and skills' (p. 59). 22. It may be objected that it is absurd to think that five year olds can produce answers to such questions. Not at all. Young children are obliged to be natural philosophers, in a way in which adults are not, in that they have to create a view of the world around them more or less from scratch. An indication of this is the insatiable curiosity of young children. 